\title{
PERBANDINGAN EFEKTIFITAS PENURUNAN KADAR BOD DAN COD PADA LIMBAH CAIR INDUSTRI TAHU MENGGUNAKAN TANAMAN KAYU APU (Pistia stratiotes) DAN TANAMAN ECENG GONDOK (Eichornia crassipes Solms)
}

\author{
Enggrit Ariana Sari, Koerniasari, Soekiran Al Jauhari
}

\begin{abstract}
Tofu waste is the waste generated in tofu manufacturing process. The Waste is generated in the form of solid and liquid wastes. The liquid waste contains organic material. When it is disposed in water without processing, it will cause pollution, such as the reduction of oxygen dissolved in the water causing disturbance on organisms living in the water.

This is an actual experimental research by using "pretest-posttest with Control Group" design. This research was conducted with 9 repetitions; each took 30 liters divided into three tubs. The data were then analyzed by using the percent decline formula.

The results showed that each treatment was effective to reduce BOD and $C O D$ with 2 days contact. BOD reduction was $49.11 \%$ and $42.87 \%$ for COD reduction by using water hyacinth plant. With apu-apu, the reduction of $B O D$ was $33.76 \%$ and COD was $36.26 \%$.

Small and medium industries experiencing problems with the quality BOD and COD level are suggested to make a pond filled with the plants to absorb the levels of BOD and COD to improve the quality of the liquid waste before it is discharged in water bodies. Government institutions are expected to continue to monitor industry that produces waste. Therefore, $B O D$ and $C O D$ levels remain below the quality standard that has been set.

Keywords :BOD, COD, Apu-Apu, Water Hyacinth, Tofu waste
\end{abstract}

\section{PENDAHULUAN}

Limbah cair merupakan bahan buangan cair yang tidak terpakai akibat dari aktifitas manusia, yang berasal dari kegiatan rutinitas aktifitas rumah tangga dan aktifitas proses industri. Selanjutnya dikenal sebagai limbah cair domestik dan limbah cair non domestik, serta limpasan air hujan yang merupakan limbah cair hasil aktifitas alam. Kedua jenis limbah cair hasil aktifitas manusia tersebut diatas umumnya banyak mengandung zat-zat polutan yang membahayakan kesehatan manusia dan lingkungan, sehingga kedua jenis limbah cair tersebut perlu mendapatkan penanganan secara benar dan tepat, mulai dari sumber limbah cair sampai pada proses pembuangan akhir, agar tidak menimbulkan gangguan kesehatan masyarakat dan lingkungan. (Purwanto, 2006:2)

Salah satu industri yang menghasilkan limbah cair dan berkembang pesat di Indonesia adalah industri tahu. Industri tahu dalam proses pengolahannya menghasilkan limbah, baik limbah padat maupun cair. Limbah cair dihasilkan dari proses pencucian, perebusan, pengepresan dan pencetakan tahu. (Angraini, 2014:2). Air limbah tersebut mengandung bahan organik, bila langsung dibuang kebadan air penerima tanpa ada nya proses pengolahan maka akan menimbulkan pencemaran, seperti menimbulkan rasa dan bau yang tidak sedap dan berkurangnya oksigen yang terlarut dalam air sehingga mengakibatkan organisme yang hidup didalam air terganggu karena kehidupannya tergantung pada lingkungan sekitarnya. Pencemaran yang dilakukan terus menerus akan mengakibatkan mati nya organisme yang ada dalam air (Farid, 2008).

Berdasarkan pernyataan tersebut perlu adanya upaya pencegahan untuk penurunan BOD dan COD dengan teknologi guna mendapatkan berbagai alternatif pengolahan limbah cair yang mudah dan relatif cepat. Dalam pengolahan limbah cair industri tahu, salah satu usaha yang dapat dilakukan adalah dengan cara mencari teknologi dengan biaya yang rendah namun efektif untuk menghilangkan bahan pencemar dalam limbah cair. Untuk mengatasi dampak tersebut sebaiknya air limbah yang dihasilkan oleh industri dilakukan pengolahan terlebih dahulu sebelum dibuang ke badan air perairan. Salah satu teknologi untuk mengatasi dampak tersebut adalah dengan mengaplikasikan sitem fitoremediasi. Metode penurunan atau penghilangan substansi toksis dalam air limbah dengan media tanaman lebih dikenal dengan istilah fitoremediasi atau pemanfaatan tanaman untuk mengekstraksi, menghilangkan, dan mendetoksifikasi polutan dari lingkungan. (Sriyana, 2006) 
Berdasarkan penelitian terdahulu yang dilakukan oleh Christina Irnani (2011) pada pembuangan limbah cair menggunakan tanaman eceng gondok dengan aplikasi sistem rawa buatan untuk menurunkan konsentrasi BOD, SS, COD, dan Ammoniak. Hasil dari penurunan adalah BOD 38,00 $\mathrm{mg} / \mathrm{l}(40,75 \%)$, COD 64,00 mg/l (33,33\%), SS $46,00 \mathrm{mg} / \mathrm{l}(20,68 \%), \mathrm{NH}_{3} 0,78 \mathrm{mg} / \mathrm{l}(25,72 \%)$, dan Phosphat $0,05 \mathrm{mg} / \mathrm{l}(28,58 \%)$ dan alternatif lain untuk menurunkan kadar DO pada penelitian yang dilakukan oleh Ervina Hermawati, Wiryanto, dan Solichatun (2005) berdasarkan morfologi tanaman kayu apu sangat cocok untuk pengolahan limbah cair dapat dimanfaatkan sebagai material penyerap (adsorben) bahan berbahaya bagi lingkungan. Tanaman kayu apu pada pengolahan limbah cair detergen yang telah dilakukan dapat menurunkan penurunan kadar DO limbah cair. Hasil penurunan limbah cair detergen setelah 14 hari kontrol atau konsentrasi $0 \%$ mengalami penurunan yang tertinggi pada perlakuan dengan tanaman kayu apu sebesar $69,27 \%$ atau dari $8,07 \mathrm{mg} / \mathrm{L}$ menjadi 2,48 $\mathrm{mg} / \mathrm{L}$.

Berdasarkan uraian di atas, maka penulis ingin memanfaatkan efesiensi tanaman kayu apu dan tanaman eceng gondok yang dua tanaman tersebut memiliki daya adsorben bahan berbaya bagi lingkungan dan cocok digunakan sebagai alat bantu penurunan kadar BOD dan COD yang berasal dari air limbah yang bayak mengandung zat organik dan dapat mencemari lingkungan yang dihasilkan oleh limbah cair industri tahu, maka penulis tertarik untuk melakukan penelitian yang berjudul "STUDI PERBANDINGAN EFEKTIFITAS PENURUNAN KADAR BOD DAN COD PADA LIMBAH CAIR INDUSTRI TAHU MENGGUNAKAN TANAMAN KAYU APU (Pistia stratiotes) DAN TANAMAN ECENG GONDOK (Eichornia crassipes Solms)"

\section{METODE PENELITIAN}

Ditinjau dari metodenya jenis penelitian ini merupakan penelitian applied experimenthal yang bertujuan untuk mengetahui penurunan kadar BOD dan COD pada air limbah cair industri tahu. Penelitian ini dilakukan untuk mengetahui pengaruh yang timbul akibat dari percobaan yang dilakukan. Penelitian ini merupakan penelitian di laboratorium. Desain penelitian ini menggunakan "Pretest-Posttest with Control Group". dalam rancangan ini hanya menggunakan kelompok subjek. Pertama dilakukan perlakuan dalam jangka waku tertentu, kemudian dilakukan pengukuran kembali untuk kedua kalinya.

Dalam melakukan penelitian perlu adanya replikasi atau pengulangan yang bertujuan agar mendapatkan data yang akurat. Adapun replikasi atau pengulangan setiap masing-masing perlakuan dapat dihitung dengan rumus: (Federer,1963 dalam Gustiansyah,2012)

$$
(p-1)(r-1) \geq 15
$$

Keterangan :

$\mathrm{p}=$ jumlah perlakuan

$r=$ replikasi

$\begin{array}{ll}(\mathrm{p}-1)(\mathrm{r}-1) & \geq 15 \\ (3-1)(r-1) & \geq 15 \\ 2(r-1) \geq 15 & \\ 2 r-2 & \geq 15 \\ 2 r & \geq 17 \\ r & \geq 8,5\end{array}$

Sehingga pengulangan dilakukan sebanyak 9 kali

\section{HASIL DAN PEMBAHASAN}

Hasil pengukuran pH limbah cair selama proses penelitian yang berlangsung sejak tanggal 4 April 2016 sampai dengan tanggal 4 Mei 2016 didapatkan hasil sebagai berikut

Tabel 1

Hasil Pengukuran Ph Limbah Cair Industri Tahu

\begin{tabular}{|c|c|c|c|c|c|c|c|c|c|c|}
\hline \multirow{3}{*}{ Pengulangan } & \multirow{3}{*}{ Tanggal } & \multicolumn{9}{|c|}{ Derajat Keasaman dan Basa $(\mathrm{pH})$} \\
\hline & & \multicolumn{3}{|c|}{ Tanpa Perlakuan } & \multicolumn{3}{|c|}{ Kayu Apu } & \multicolumn{3}{|c|}{ Eceng Gondok } \\
\hline & & 1 & 2 & 3 & 1 & 2 & 3 & 1 & 2 & 3 \\
\hline 1 & 4-6 April & 5 & 6 & 6 & 5 & 5 & 6 & 5 & 6 & 5 \\
\hline 2 & 6-8 April & 5 & 5 & 6 & 6 & 5 & 6 & 5 & 5 & 5 \\
\hline 3 & 11-13 April & 6 & 5 & 6 & 6 & 5 & 5 & 6 & 5 & 6 \\
\hline 4 & 13-15 April & 6 & 6 & 5 & 6 & 5 & 5 & 6 & 6 & 6 \\
\hline 5 & 18-20 April & 5 & 6 & 6 & 5 & 5 & 6 & 5 & 5 & 5 \\
\hline 6 & 20-22 April & 6 & 5 & 6 & 6 & 6 & 5 & 6 & 6 & 6 \\
\hline 7 & 25-27 April & 5 & 5 & 6 & 5 & 6 & 6 & 5 & 6 & 5 \\
\hline 8 & 27-29 April & 6 & 6 & 6 & 6 & 5 & 5 & 6 & 6 & 6 \\
\hline 9 & 2-4 Mei & 6 & 5 & 6 & 6 & 6 & 5 & 6 & 5 & 5 \\
\hline
\end{tabular}


Selama proses penurunan kadar BOD dan COD dengan menggunakan tanaman kayu apu dan tanaman eceng gondok dilakukan pengukuran $\mathrm{pH}$ setiap harinya. Dari hasil pengukuran dalam penelitian ini diketahui bahwa $\mathrm{pH}$ limbah cair belum cukup optimal untuk tersedianya unsur hara tanaman yaitu berkisar 5-6, ini dikarenakan air limbah industri tahu sifatnya yang cenderung asam dan pada keadaan asam ini akan terlepas zat-zat yang mudah menguap. Hal ini mengakibatkan limbah cair industri tahu mengeluarkan bau busuk. pH limbah cair yang optimal yaitu sebesar 7 dimana menurut Ratnani (2010) dapat mendukung adanya kadar unsur hara yang tinggi juga sangat besar. Sesuai dengan pendapat Ratnani (2010) pH yang diperkenankan untuk pertumbuhan tanaman eceng gondok yaitu sekitar $6-7,5$ dan $\mathrm{pH}$ di bawah 4,2 dapat meracuni pertumbuhan tanaman eceng gondok sehingga eceng gondok dapat mati. Adapun rentang $\mathrm{pH}$ yang diperlukan untuk tanaman kayu

Tabel 2

Hasil Pengukuran Suhu Limbah Cair Industri Tahu

\begin{tabular}{|c|c|c|c|c|c|c|c|c|c|c|}
\hline \multirow{3}{*}{ Pengulangan } & \multirow{3}{*}{ Tanggal } & \multicolumn{9}{|c|}{ Suhu ${ }^{\circ} \mathrm{C}$} \\
\hline & & \multicolumn{3}{|c|}{ Tanpa Perlakuan } & \multicolumn{3}{|c|}{ Kayu Apu } & \multicolumn{3}{|c|}{ Eceng Gondok } \\
\hline & & 1 & 2 & 3 & 1 & 2 & 3 & 1 & 2 & 3 \\
\hline 1 & 4-6 April & 26 & 26 & 27 & 26 & 28 & 27 & 26 & 27 & 27 \\
\hline 2 & 6-8 April & 27 & 26 & 28 & 27 & 27 & 27 & 27 & 28 & 26 \\
\hline 3 & 11-13 April & 26 & 28 & 28 & 26 & 27 & 27 & 26 & 26 & 27 \\
\hline 4 & 13-15 April & 26 & 26 & 28 & 26 & 28 & 26 & 26 & 27 & 28 \\
\hline 5 & 18-20 April & 28 & 27 & 28 & 28 & 27 & 26 & 28 & 28 & 27 \\
\hline 6 & 20-22 April & 27 & 27 & 28 & 27 & 26 & 27 & 27 & 28 & 28 \\
\hline 7 & 25-27 April & 26 & 27 & 27 & 26 & 27 & 27 & 26 & 27 & 27 \\
\hline 8 & 27-29 April & 27 & 27 & 28 & 27 & 26 & 27 & 27 & 27 & 26 \\
\hline 9 & 2-4 Mei & 28 & 27 & 27 & 28 & 27 & 27 & 28 & 27 & 27 \\
\hline
\end{tabular}

Suhu juga merupakan salah satu faktor penting dalam penanganan limbah. Selama proses penurunan kadar BOD dan COD dengan menggunakan tanaman kayu apu dan tanaman eceng gondok dilakukan pengukuran suhu setiap harinya. Berdasarkan hasil pengukuran suhu selama apu untuk dapat tumbuh dengan baik yaitu sekitar $6-7$.

Konsentrasi ion hidrogen $(\mathrm{pH})$ merupakan parameter penting untuk kualitas air dan air limbah. $\mathrm{pH}$ sangat berperan dalam kehidupan biologi dan mikrobiologi. pH sangat berpengaruh dalam proses pengolahan air limbah. Sesuai Peraturan Menteri Lingkungan Hidup Republik Indonesia Nomor 5 Tahun 2014 Tentang Baku Mutu Air Limbah, baku mutu pH yang ditetapkan sebesar 6-9. Pengaruh yang terjadi apabila $\mathrm{pH}$ terlalu rendah adalah penurunan oksigen terlarut dan konsumsi oksigen menurun.

Hasil pengukuran suhu limbah cair selama proses penelitian yang berlangsung sejak tanggal 4 April 2016 sampai dengan tanggal 4 Mei 2016 didapatkan hasil sebagai berikut:

$$
\text { Tabel } 3
$$

penelitian diketahui bahwa suhu berkisar antara 26 $-28^{\circ} \mathrm{C}$

Syarat pertumbuhan yang optimum bagi eceng gondok adalah air yang dangkal, ruang tumbuh luas, air tenang, cukup cahaya matahari, suhu antara $20-30 \circ \mathrm{C}$

Hasil rata-rata pengukuran kadar BOD dan COD (pengulangan pertama sampai dengan kesembilan)

\begin{tabular}{|c|c|c|c|c|}
\hline \multirow{2}{*}{ No } & \multirow{2}{*}{ Perlakuan } & \multirow{2}{*}{ Waktu } & \multicolumn{2}{|c|}{ Hasil Rata-rata (mg/L) } \\
\hline & & & BOD & COD \\
\hline \multirow{3}{*}{1} & \multirow{3}{*}{ Tanpa Tanaman } & Awal Pengambilan & 299 & 400,7 \\
\hline & & Setelah 2 Hari & 287,8 & 381,6 \\
\hline & & $\%$ Penurunan & $3,75 \%$ & $4,77 \%$ \\
\hline \multirow{3}{*}{2} & \multirow{3}{*}{ Kayu Apu } & Awal Pengambilan & 322,6 & 555,1 \\
\hline & & Setelah 2 Hari & 213,7 & 353,8 \\
\hline & & $\%$ Penurunan & $33,76 \%$ & $36,26 \%$ \\
\hline \multirow{3}{*}{3} & \multirow{3}{*}{ Eceng Gondok } & Awal Pengambilan & 330,3 & 489,4 \\
\hline & & Setelah 2 Hari & 141,1 & 279,6 \\
\hline & & $\%$ Penurunan & $49,11 \%$ & $42,87 \%$ \\
\hline
\end{tabular}


BOD menunjukan banyaknya oksigen yang diperlukan untuk menguraikan bahan organik oleh bakteri aerobik melalui proses biologis (biological oxidation) secara dekomposisi aerobik. Angka BOD menggambarkan jumlah oksigen yang diperlukan oleh bakteri untuk menguraikan (mengoksidasi) hampir semua zat organik yang terlarut dan sebagaian zat-zat organis yang tersuspensi di dalam air.

COD Merupakan jumlah oksigen yang dibutuhkan untuk mengoksidasi bahan organik dalam air secara kimiawi. Jika bahan organik yang belum diolah dibuang ke badan perairan, maka bakteri akan menggunakan oksigen untuk proses pembusukannya. COD biasanya lebih tinggi dari pada nilai BOD karena bahan buangan yang dapat dioksidasi melalui proses kimia lebih banyak dari pada bahan buangan yang dapat dioksidasi melalui proses biologi.

Berdasarkan tabel IV.12 diketahui bahwa terjadi penurunan kadar BOD dan COD dalam limbah cair industri tahu, jadi tanaman kayu apu dan tanaman eceng gondok berpengaruh nyata terhadap penurunan kadar BOD dan COD. Pada tanaman kayu apu rata-rata kadar BOD sebelum diberi perlakuan adalah $322,6 \mathrm{mg} / \mathrm{L}$ dan sesudah diberi perlakuan adalah $213,7 \mathrm{mg} / \mathrm{L}$ dengan hasil penurunan rata-rata kadar BOD sebesar 33,76\% sedangkan pada tanaman eceng gondok rata-rata kadar BOD sebelum diberi perlakuan $330,3 \mathrm{mg} / \mathrm{L}$ dan sesudah diberi perlakuan adalah 141,1 mg/L dengan hasil penurunan rata-rata kadar BOD sebesar $49,11 \%$. Untuk penurunan rata-rata kadar COD pada tanaman kayu apu sebelum diberi perlakuan adalah $555,1 \mathrm{mg} / \mathrm{L}$ dan sesudah diberi perlakuan adalah $353,8 \mathrm{mg} / \mathrm{L}$ dengan hasil penurunan rata-rata kadar COD sebesar 36,26\% sedangkan pada tanaman eceng gondok rata-rata kadar COD sebelum diberi perlakuan 489,4 mg/L dan sesudah diberi perlakuan adalah $279,6 \mathrm{mg} / \mathrm{L}$ dengan hasil penurunan rata-rata kadar BOD sebesar $42,87 \%$. Pada percobaan didalam reaktor tanpa perlakuan didapatkan hasil rata-rata kadar BOD sebesar $299 \mathrm{mg} / \mathrm{L}$ pada 0 hari dan waktu 2 hari mendapatkan hasil rata-rata kadar BOD sebesar $287,8 \mathrm{mg} / \mathrm{L}$ dengan penurunan sebesar 3,75\% sedangkan rata-rata kadar COD pada waktu 0 hari sebesar 400,7 mg/L dan pada waktu 2 hari sebesar 381,6 dengan penurunan sebesar $4,77 \%$.

Penurunan kadar BOD dan COD dapat dijelaskan bahwa pemberian perlakuan dengan merendam tanaman kayu apu dan tanaman eceng gondok pada limbah cair industri tahu dapat menurunkan kadar BOD dan COD. Pemberian tanaman memberikan suplai oksigen tinggi, selain itu hasil fotosintesis yang dilakukan oleh tanaman juga dapat mensuplai kebutuhan akan oksigen yang akan digunakan untuk menguraikan bahan organik yang terdapat di dalam air limbah. Akar pada tumbuhan juga berperan aktif dalam penurunan kadar BOD dan COD. Akar tumbuhan dapat menyerap kadar BOD dan COD yang terkandung dalam limbah cair industri tahu.

Pada perlakuan tanpa tanaman tidak terjadi penutupan permukaan air oleh tanaman sehingga oksigennya terlarut dapat menyebabkan penurunan kadar BOD dan COD walaupun dalam jumlah yang kecil. Tidak adanya penutupan tanaman pada media uji menyebabkan oksigen bebas sangat mudah untuk larut dalam air. Pada perlakuan dengan tanaman, luas permukaan yang terkena udara bebas lebih sedikit sehingga nilai oksigen terlarut menurun lebih cepat. Selain itu area penutupan permukaan air limbah oleh kedua tanaman juga mempengaruhi oksigen bebas untuk larut dalam air limbah tersebut. Namun oksigen tersebut diserap oleh tanaman untuk melakukan fotosintesis.

Jadi rata-rata kadar BOD sesudah diberi perlakuan dengan tanaman kayu apu sebesar 213,7 $\mathrm{mg} / \mathrm{L}$ dan rata-rata kadar COD sebesar $353,8 \mathrm{mg} / \mathrm{L}$ sedangkan rata-rata kadar BOD sesudah diberi perlakuan dengan tanaman eceng gondok sebesar $141,1 \mathrm{mg} / \mathrm{L}$ dan rata-rata kadar COD sebesar 279,6 $\mathrm{mg} / \mathrm{L}$. Untuk rata-rata kadar BOD tanpa perlakuan sebesar 287,8 mg/L dan rata-rata kadar COD sebesar 381,6 mg/L. Menurut Peraturan Menteri Lingkungan Hidup Republik Indonesia Nomor 5 Tahun 2014 Tentang Baku Mutu Air Limbah, kadar maksimum BOD dalam limbah cair sebesar 150 $\mathrm{mg} / \mathrm{L}$ dan kadar maksimum COD sebesar 300 mg/L. Maka hasil penurunan yang diberi perlakuan dengan menggunakan tanaman eceng gondok memenuhi persayaratan baku mutu.

\section{KESIMPULAN}

1. Selama proses penelitian dilakukan pengukuran $\mathrm{pH}$ dan suhu limbah cair industri tahu. Hasil pengukuran $\mathrm{pH}$ limbah cair selama pengukuran mulai pengulangan pertama sampai dengan pengulangan kesembilan sebesar $5-6$ sedangkan suhunya sebesar $26-28^{\circ} \mathrm{C}$.

2. Kadar BOD dan COD tanpa perlakuan sebelum dilakukan proses sebesar $299 \mathrm{mg} / \mathrm{L}$ dan 400,7 $\mathrm{mg} / \mathrm{L}$. Adapun kadar BOD dan COD sebelum diberi perlakuan dengan tanaman kayu apu sebesar 322,6 mg/L dan 555,1 mg/L sedangkan kadar BOD dan COD sebelum diberi perlakuan dengan tanaman eceng gondok sebesar 330,3 $\mathrm{mg} / \mathrm{L}$ dan 489,4 mg/L.

3. Kadar BOD dan COD tanpa perlakuan setelah 2 hari sebesar 287,8 mg/L dan 381,6 mg/L. Adapun kadar BOD dan COD setelah diberi perlakuan dengan tanaman kayu apu sebesar 213,7 mg/L dan 353,8 mg/L sedangkan kadar BOD dan COD setelah diberi perlakuan dengan tanaman eceng gondok sebesar $141,1 \mathrm{mg} / \mathrm{L}$ dan $279,6 \mathrm{mg} / \mathrm{L}$

4. Kadar BOD dalam limbah cair industri tahu pada masing-masing perlakuan didapatkan penurunan sebesar 3,75\% pada reaktor tanpa perlakuan, 33,76\% pada reaktor yang diberi perlakuan dengan tanaman kayu apu, dan $49,11 \%$ pada reaktor yang diberi perlakuan 
dengan tanaman eceng gondok sedangkan kadar COD dalam limbah cair industri tahu pada masing-masing perlakuan didapatkan penurunan sebesar $4,77 \%$ pada reaktor tanpa

5. Setelah 2 hari daun kayu apu mulai layu dan tampak menguning sedangkan daun eceng gondok sebagian tetap berwarna hijau dan pada batang eceng gondok sudah mulai menguning. Maka lebih efektif eceng gondok daripada kayu apu dalam efektifitas penurunan kadar BOD dan COD.

6. Menurut Peraturan Menteri Lingkungan Hidup Republik Indonesia Nomor 5 Tahun 2014 Tentang Baku Mutu Air Limbah, kadar maksimum BOD dalam limbah cair sebesar 150 $\mathrm{mg} / \mathrm{L}$ dan kadar maksimum COD sebesar 300 $\mathrm{mg} / \mathrm{L}$. Maka hasil penurunan yang diberi perlakuan dengan menggunakan tanaman eceng gondok memenuhi persayaratan baku mutu dan lebih efektif daripada hasil penurunan

\section{DAFTAR PUSTAKA}

Chandra, Budiman. 2005. Pengantar Kesehatan Lingkungan. Jakarta. Penerbit Buku Kedokteran.

Farid., 2008. Pengaruh Perubahan Kuat Arus Listrik Terhadap Penyisihan Bahan Organik Limbah Cair Industri Tahu Dengan Proses Plasma. Skripsi Jurusan Teknik Lingkungan FTSP UPN "Veteran" Jawa Timur, Surabaya. Surabaya.

Gustiansyah, Rizki Jaka.2012.Efek Susu Kacang Kedelai (Glycine max (L) Merr) Terhadap Kadar Asam Urat Darah Tikus Putis Jantan Yang Diinduksi Kalium Oksonat. FMIPA. Program Studi Farmasi. Universitas Indonesia. Depok

Hermawati,Ervina.,Wiryanto.,Solichatun.2005. Fitoremediasi Limbah Detergen Menggunakan Kayu Apu (Pistia stratoites) dan Genjer (Limnocharis flava). Surakarta, Universitas Sebelas Maret : Jurusan Biologi FMIPA

Irnani, Christina, 2011. Aplikasi Sistem Hidroponik Menggunakan Tanaman Eceng Gondok untuk Menurunkan Konsentrasi BOD, SS, $C O D$, dan Ammoniak. Karya Tulis Ilmiah. Jurusan Kesehatan Lingkungan, Poltekkes Kemenkes Surabaya. Surabaya

Irmanto, Suyata. 2010. Penurunan Kadar Amonia, Nitrit, Dan Nitrat Limbah Cair Industri Tahu Menggunakan Arang Aktif Dari Ampas Kopi. Skripsi. Program Studi Kimia, Jurusan MIPA Fakultas Sains dan Teknik UNSOED, Purwokerto. Purwokerto.

Isyuniarto, Widdi Usada, Suryadi, Agus Purwadi. 2006. Pengolahan Limbah Cair Industri Tahu Dengan Teknik Lucutan Plasma. Pusat Teknologi Akselerator dan Proses BahanBATAN perlakuan, $36,26 \%$ pada reaktor yang diberi perlakuan dengan tanaman kayu apu, dan $42,87 \%$ pada reaktor yang diberi perlakuan dengan tanaman eceng gondok yang diberi perlakuan dengan menggunakan tanaman kayu apu.

\section{SARAN}

Disarankan bagi industri kecil menengah yang mengalami masalah dengan kualitas kadar BOD dan COD yang tinggi dapat membuat kolam penampungan limbah terlebih dahulu yang diisi dengan tanaman eceng gondok untuk menyerap kadar BOD dan COD agar dapat dilakukan perbaikan kualitas limbah cair tersebut sebelum dibuang di badan air. Bagi institusi pemerintahan untuk terus memantau industri yang menghasilkan limbah agar kadar BOD dan COD tetap dibawah baku mutu yang sudah ditetapkan.

Peraturan Menteri No. 5 Tahun 2014 tentang Baku Mutu Air Limbah

Peraturan Pemerintah RI No. 82 tahun 2001 Tentang Pengelolaan Kualitas Air Dan Pengendalian Pencemaran Air

Purwanto, Didik Sugeng, 2006. Pengolahan Limbah Cair. Surabaya. Penerbit Dua Tujuh

Ratnani, Rita Dwi., Indah Hartanti dan Laeli Kurniasari. 2010. Pemanfaatan Eceng Gondok (Eichornia Crassipes) Untuk Menurunkan Kandungan COD (Chemical Oxygen Demond), Ph, Bau, dan Warna Pada Limbah Cair Tahu. Laporan Penelitian. Fakultas Teknik, Universitas Wahid Hasyim. Semarang

Safitri, Silviana. 2009. Perencanaan Sistem Pengolahan Limbah Cair Industri Tahu PT. AS Tanah Baru Depok. Skripsi. Program Studi Kesehatan Masyarakat, Jurusan Kesehatan Masyarakat, Universitas Indonesia. Depok

Sitompul, Debora F., Mumu Sutisna dan Kancitra Pharmawati, 2013. Pengolahan Limbah Cair Hotel Aston Braga City Walk Dengan Proses Fitoremediasi Menggunakan Tumbuhan Eceng Gondok.

Sriyana, H.Y., 2006, Kemampuan Eceng Gondok dalam Menurunkan Kadar Pb(II) dan Cr (VI) Pada Limbah dengan Sistem Air Mengalir dan Sistem Air Menggenang, Tesis S2, Fakultas Teknik, Jurusan Teknik Kimia UGM,Yogyakarta.

Sutriswati Rahayu, Endang. 2012. TeknologI Proses Produksi Tahu. Yogyakarta. Penerbit Kanisius.

Suyono dan Budiman. 2010. IImu Kesehatan Masyarakat. Jakarta. Penerbit Buku Kedokteran 